September 2006

\title{
Social environment and depression among pregnant women in urban areas of Pakistan: importance of social relations.
}

\author{
Ambreen Kazi \\ Aga Khan University \\ Zafar Fatmi \\ Aga Khan University, zafar.fatmi@aku.edu \\ Juanita Hatcher \\ Aga Khan University \\ Muhammad Masood Kadir \\ Aga Khan University \\ Unaiza Niaz \\ Aga Khan University \\ See next page for additional authors
}

Follow this and additional works at: http://ecommons.aku.edu/pakistan_fhs_mc_chs_chs

Part of the Community Health Commons, Environmental Studies Commons, Female Urogenital Diseases and Pregnancy Complications Commons, Obstetrics and Gynecology Commons, $\underline{\text { Social }}$ Psychology and Interaction Commons, and the Urban Studies and Planning Commons

\section{Recommended Citation}

Kazi, A., Fatmi, Z., Hatcher, J., Kadir, M. M., Niaz, U., Wasserman, G. A. (2006). Social environment and depression among pregnant women in urban areas of Pakistan: importance of social relations.. Social Science and Medicine, 63(6), 466-476.

Available at: http://ecommons.aku.edu/pakistan_fhs_mc_chs_chs/178 
Authors

Ambreen Kazi, Zafar Fatmi, Juanita Hatcher, Muhammad Masood Kadir, Unaiza Niaz, and Gail A. Wasserman 


\title{
Social environment and depression among pregnant women in urban areas of Pakistan: Importance of social relations
}

\author{
Ambreen Kazi ${ }^{\mathrm{a}, *}$, Zafar Fatmi ${ }^{\mathrm{a}}$, Juanita Hatcher ${ }^{\mathrm{a}}$, Muhammad Masood Kadir ${ }^{\mathrm{a}}$, \\ Unaiza Niaz ${ }^{\mathrm{a}}$, Gail A. Wasserman ${ }^{\mathrm{b}}$ \\ ${ }^{a}$ Department of Community Health Sciences, Aga Khan University, Karachi, Pakistan \\ ${ }^{\mathrm{b}}$ Division of Child and Adolescent Psychiatry, Columbia University, New York City, New York
}

Available online 23 June 2006

\begin{abstract}
Aspects of the social environment, including social conditions (socio-economic status, household situations, chronic illnesses) and social relations (attitude and behaviors of relations) are major determinants of depression among women. This study evaluates the relative power of social relations and social conditions in predicting depression among pregnant women in Pakistan. In the qualitative phase of the study, social environmental determinants were identified through literature search, and experts' opinions from psychologists, psychiatrists, gynecologists, sociologists and researchers. Along with this, 79 in-depth interviews were conducted with pregnant women drawn from six hospitals (public and private) and two communities in Karachi, Pakistan. Identified determinants of depression were grouped into themes of social conditions and social relations and pregnancy-related concerns. In the study's quantitative phase, the relative power of the identified themes and categories, based on their scores for predicting depression (determined by the Center for Epidemiological Studies-Depression Scale (CES-D scale)), was determined through multivariate linear regression. Social environmental determinants of pregnant women were described under the themes and categories of (1) social relations: involving husband, in-laws and children; (2) social conditions: involving the economy, illness, life events, household work, environmental circumstances and social problems; and (3) pregnancy-related concerns i.e. symptoms of pregnancy, changes during pregnancy, dependency and concern for unborn baby. Multivariate analysis found that among these themes, social relations and pregnancy-related concerns were significantly associated with total CES-D scores. Among the categories besides increasing age and less education, husband, in-laws, household work and pregnancy symptoms were significantly associated with total CES-D scores. The study highlights the importance of social relations compared to social conditions for determining depression in pregnant women.
\end{abstract}

(C) 2006 Elsevier Ltd. All rights reserved.

Keywords: Pakistan; Social environment; Pregnancy; Social conditions; Social relations; Urban area

\section{Introduction}

The studies have found high a prevalence of depression (28-57\%) among women in Pakistan

${ }^{*}$ Corresponding author. Tel.: + 922148114931.

E-mail address: ambreen.kazi@aku.edu (A. Kazi).
(Husain, Creed, \& Tomenson, 2000; Mumford, Minhas, Akhtar, Akhter, \& Mubbashar, 2000; Ali et al., 2002). The social environment has been identified as one of the major determinants of depression among women (Rabbani \& Raja, 2000; Husain, Gater, Tomenson, \& Creed, 2004; Niaz, 2001; Riso, Miyatake, \& Thase, 2002), Social 
environment is often hostile to women in Pakistan (Husain et al., 2000; Mumford et al., 2000; Mumford, Nazir, Jilani, \& Baig, 1996; Mumford, Saeed, Ahmad, Latif, \& Mubbashar, 1997). Women are encouraged to be subservient, and wife battering, conflict with spouse and in-laws are common problems in Pakistan (Niaz, 2001).

Although it was thought that pregnancy may act as a protection against mental illnesses, a high prevalence of depression among pregnant women contradicts such beliefs (Bennett, Einarson, Taddio, Koren, \& Einarson, 2004). A study conducted in a rural area of Pakistan found that $25 \%$ of women during pregnancy and $28 \%$ in the postpartum period suffered from depression (Rahman, Iqbal, \& Harrington, 2003). Pregnant women who were depressed had more likely experienced life-threatening events and lack of social support (Rahman et al., 2003). Studies indicate that depression leads to adverse pregnancy outcomes such as preterm and low birth weight babies (Dole et al., 2003; Mulder et al., 2002; Wadhwa et al., 2001). In spite of this high prevalence, no study has looked at the relative importance of various determinants in the social environment in predicting depression among pregnant women in Pakistan.

Many studies have measured social environmental variables in terms of income, education, occupation and number of social supports (Koniak-Griffin, Lominska, \& Brecht, 1993). These might be called social conditions which include socio-economic status (SES), major life events, relatives' health status, household responsibilities and supports (Nilsson, Engberg, Nilsson, Karlsmose, \& Lauritzen, 2003). In addition, a woman's social relations should be such as the quality of relationship with her husband, in-laws, parents and children (Barnet, Joffe, Duggan, Wilson, \& Repke, 1996; Nitz, Ketterlinus, \& Drandt, 1995; Stuchbery, Matthey, \& Barnett, 1998). Concerns related to pregnancy are an added burden during pregnancy and may include signs and symptoms of pregnancy, changes due to pregnancy and concern for the baby (Huizink, Robles de Median, Mulder, Visser, \& Buitelaar, 2003; Stotland, 1995). Therefore, it is prudent to study pregnant women's perceptions of social conditions, social relations and pregnancy-related concerns together as potential determinants of depression.

The objective of this study was to measure the prevalence of depression among pregnant women and to determine the relative importance of social conditions, social relations and pregnancyrelated concerns for predicting depression among pregnant women in Karachi, an urban area of Pakistan.

\section{Methods}

The study was conducted in Karachi, the capital city of the province of Sindh, Pakistan, during December 2003 to September 2004. While most of the residents of Karachi are Urdu-speaking, it has considerable socio-economic and ethnic diversity and has a population of more than 14 million. The majority of the women typically stay at home and their lives are centered on their families. Girls and boys receive different levels of education: $70 \%$ of males and $57 \%$ of female are literate in Karachi (Government of Pakistan, 1998).

The study had two parts the qualitative part during which social environmental determinants were identified and the quantitative part during which prevalence of depression and relative importance of social determinants for depression were analyzed. Phase 1 was conducted from July 2003 to May 2004. Phase 2 was undertaken during JuneSeptember 2004.

\section{Phase 1-Qualitative study}

Initially, textbooks and published literature regarding social environment were reviewed. Interviews were conducted with 25 experts to identify determinants. These experts included psychologists, psychiatrists, gynecologists, sociologists, social workers and researchers. Many of these experts were working at Aga Khan University \& Hospital and had more than 10 years experience of working with pregnant women. In addition, gynecologists belonging to the study hospitals and organizations were also approached for their expert opinion (list of the organizations is given in Table 1).

\section{Interviews with pregnant women}

Based on initial work, semi-structured guidelines were developed to interview pregnant women. Guidelines included inquiry into all the issues which pregnant women perceived as "difficulties" or "stressful situations" in their life. Seventy-nine indepth interviews were conducted with pregnant women in the local language, Urdu, by a female to generate a list of determinants. Women who had difficulty in understanding or speaking Urdu were 
not included in the study. On an average, each interview took one to one and a half hour. Sample size was based on sampling to redundancy, i.e. interviews were stopped when no new determinants were being identified. Also pregnant women coming for their antenatal checkup were selected from six hospitals (public and private) (Table 1). Pregnant women in the two communities were approached with the help of the local organizations working in the area (see Table 1). These sites were purposely selected to include socio-economically diverse population in order to capture a wide range of determinants. Written consent was taken from the pregnant women and their husbands (when requested by women) after explaining the purpose of the study. Consideration was also given to include pregnant women of all parities and trimesters. Socio-demographic profile of pregnant women for the qualitative phase is given in Table 2.

\section{Pretesting and phrasing of items on determinants}

Identified determinants were pretested on a separate sample of 70 pregnant women. After every 10 interviews, identified problems were discussed by the research team and determinants were rephrased and tested again for clarity and content. Overlapping statements were dropped and eventually 89 items were finalized with the help of the experts (mentioned above).

\section{Phase 2-Quantitative study}

During this phase, 292 pregnant women were interviewed during their antenatal visits. They were selected from four hospitals in Karachi catering to different socio-economic groups. Among the four hospitals, Public Health School provides outpatient maternal and child care preventive and curative services free-of-charge to women and children of lower socio-economic group. Aziza Husseini Hospital and Aga Khan Hospital for Women, Karimabad are two private hospitals that provide fee-based services to the middle socio-economic strata of pregnant women. Mid-East Hospital Clifton is a private hospital that serves higher socio-economic group of pregnant women (Table 1).

Female psychologists and sociologists were provided with a week long training for conducting the interviews. Interviews were conducted in the while women were waiting for their antenatal checkup. Women who had difficulty in speaking or understanding Urdu were not included in the study. Each woman was first approached by the study coordinator who explained the study purpose and asked for a written consent. If a woman consented, she was guided to a separate room for the detailed interview. On average, each interview lasted $45 \mathrm{~min}$. The interviewer read out 89 questions concerned with the 13 categories of potential determinants. Women responses were marked (1) if the item was

Table 1

Institutions and hospitals taken in the study to interview pregnant women during the Qualitative and Quantitative phases in Karachi

No. of pregnant women

Phase 1-Qualitative study

(a) Communities

1. Malir colony

2. Zia colony of Landhi

9

12

(b) Hospitals and MCH centers

1. Lyari Community Development Program maternal and child health center 12

2. Civil Hospital Karachi

3. Jinnah Postgraduate Medical Center

4. Aga Khan Maternity Health Center Karimabad

5. Liaquat National Hospital

6. Aga Khan University Hospital

Total

Phase 2-Quantitative study

1. Aga Khan Maternity Center (AKMC) Karimabad (middle SES) 50

2. Aziza Husseini Hospital, Gulberg (middle SES) $\quad 70$

3. Public Health School (lower SES) 101

4. Mideast Hospital (high SES) $\quad 71$

Total 
Table 2

Socio-demographic profile of pregnant women in phase 1 and 2 in Karachi, Pakistan

\begin{tabular}{|c|c|}
\hline Phase 1-Qualitative study & $n=79(\%)$ \\
\hline Age (mean) & $27.3(\mathrm{SD} 4.7)$ years \\
\hline \multicolumn{2}{|l|}{ Educational status of women } \\
\hline No Schooling & $29(36.7)$ \\
\hline Primary $(1-5)$ & $11(13.9)$ \\
\hline Secondary (6-10) & $12(15.1)$ \\
\hline Graduation (11-14) & $16(20.2)$ \\
\hline Professional & $11(13.9)$ \\
\hline \multicolumn{2}{|l|}{ Mother tongue } \\
\hline Urdu & $37(46.8)$ \\
\hline Sindhi & $14(17.8)$ \\
\hline Balochi & $14(17.8)$ \\
\hline Punjabi & $7(8.8)$ \\
\hline Miscellaneous $^{\mathrm{a}}$ & $7(8.8)$ \\
\hline \multicolumn{2}{|l|}{ Educational status of husband } \\
\hline No Schooling & $25(31.6)$ \\
\hline Primary $(1-5)$ & $4(5.0)$ \\
\hline Secondary $(6-10)$ & $21(26.5)$ \\
\hline Graduation (11-14) & $10(12.6)$ \\
\hline Professional & $19(24.0)$ \\
\hline \multicolumn{2}{|l|}{ Occupation of women } \\
\hline Housewives & $50(63.2)$ \\
\hline Working & $29(36.8)$ \\
\hline \multicolumn{2}{|l|}{ Occupation of husband } \\
\hline White collar workers & $25(31.6)$ \\
\hline Blue collar workers & $49(62.0)$ \\
\hline Jobless & $5(6.3)$ \\
\hline \multicolumn{2}{|l|}{ Income group ${ }^{\mathrm{b}}$} \\
\hline$\leqslant 5000$ Pak rupees $(60$ Pak Rs $=1$ US $\$)$ & $28(37.8)$ \\
\hline$>5000$ Pak rupees & $46(62.2)$ \\
\hline \multicolumn{2}{|l|}{ Gravida } \\
\hline Primigravida (first pregnancy) & $27(34.2)$ \\
\hline Multigravida (2-4 pregnancies) & $39(49.4)$ \\
\hline $\begin{array}{l}\text { Grand-multigravida (5th or more } \\
\text { pregnancies) }\end{array}$ & $13(16.4)$ \\
\hline \multicolumn{2}{|l|}{ Trimester of pregnancy } \\
\hline 1st (1-3 months) & $12(15.2)$ \\
\hline 2nd (4-6 months) & $17(21.5)$ \\
\hline 3rd (7-9 months) & $50(63.3)$ \\
\hline Phase 2-Quantitative study & $n=292(\%)$ \\
\hline Age (mean) & $25.8(\mathrm{SD} 4.5)$ years \\
\hline \multicolumn{2}{|l|}{ Education } \\
\hline No Schooling & $39(13.4)$ \\
\hline Primary $(1-5)$ & $21(7.3)$ \\
\hline Secondary $(6-10)$ & $57(19.6)$ \\
\hline Graduation (11-14) & $140(48.6)$ \\
\hline Professional & $33(11.4)$ \\
\hline \multicolumn{2}{|l|}{ Trimester of pregnancy ${ }^{\mathrm{b}}$} \\
\hline 1st (1-3 months) & $42(16)$ \\
\hline 2nd (4-6 months) & $100(38)$ \\
\hline 3rd (7-9 months) & $121(46)$ \\
\hline
\end{tabular}

Table 2 (continued)

$\begin{array}{lr}\text { Gravida } & \\ \text { Primigravida (first pregnancy) } & 116(39.7) \\ \text { Multigravida (2nd onwards pregnancy) } & 176(60.3) \\ \text { History of abortion } & 74(26.0)\end{array}$

anclude Pushto, Memon, Gujrati, Bengali.

${ }^{\mathrm{b}}$ Missing number are due to non-response.

applicable (1) and (0) if not applicable in the past month. An index was developed by calculating the total score for each of the three themes and 13 categories as in Appendix A. For example, in the husband category, there were 10 questions; therefore, the possible score for a pregnant woman would range between 0 and 10 . The refusal rate $<5 \%$.

The translated version (in Urdu language) of Center for Epidemiological Studies-Depression (CES-D) scale was administered by a separate interviewer (blind) to the same women. CES-D is a multicultural validated instrument and has been used in many countries including India and Bangladesh to measure depression among a variety of populations including pregnant women (Gavin et al., 2005; Jain, Sanon, Sadowski, \& Hunter, 2004; Orr, James, \& Blackmore Prince, 2002; Sharp \& Lipsky, 2002; Tsutsumi et al., 2004). CES-D consists of 20 items. Each item has a score range of $0-3$. Therefore, an individual score of women on the CES-D scale may range from 0 to 60 . A cut-off of 16 and above has been recommended to diagnose depression. Below this level, the scale determines milder depressive symptoms (Radloff, 1977). The alpha coefficient of the translated version of CES-D scale among Karachi sample was 0.88 .

Data were analyzed with identifier numbers by a separate person to maintain confidentiality. Counseling was provided to those women who were diagnosed as depressed by the psychologist or they were referred for further assessment and treatment. The study was started after getting approval from the Ethical Review Committee of the Aga Khan University.

\section{Analysis plan}

The identified potential determinants were grouped into themes of: social relations, social conditions and pregnancy-related concerns. Infrequent determinants $(<5 \%)$ were not included in the 
list. Within each theme, categories were identified for similar issues (see Appendix B).

The scores on all quantitatively assessed variables were analyzed as continuous variables. Univariate linear regressions between scores of major themes and categories and total CES-D scale scores were conducted to investigate at the association between the determinants and depression. In addition, associations between age, education and total CES-D scores were also determined.

Finally, two separate multivariate analysis models were developed to determine the independent effect of the identified determinants with total CESD scores, with major themes and categories, separately.

\section{Results}

\section{Phase 1-Qualitative results}

In qualitative phase, the mean age of pregnant women was 27.3 (SD 4.7) years. The majority were Urdu speaking. About $37 \%$ were uneducated and $63 \%$ were housewives and $34 \%$ were primigravida (Table 2).

The social environmental framework for pregnant women (with themes and categories) is presented in Fig. 1. The determinants were reviewed in depth by 25 experts (see "methodology" for details) to categorize them into themes of Social Conditions, Social Relations and Pregnancy-Related Concerns. The items related to the pregnant women's social relationship with her husband, children, parents and in-laws, in a Pakistani context, were included under Social Relations. Determinants related to the characteristics of the pregnant woman and her environment were called Social Conditions and included economic problems, health status, household issues, personal and social problems. Pregnancy-related concerns included general appraisal of pregnancy such as pregnancy symptoms, pregnancy-related changes, dependency due to pregnancy and concern for unborn baby.

Descriptive statistics (mean, SD and range) of the index of determinants for themes and categories are given in Table 3. Out of 88, 18 determinants were related to social relations, 44 to social conditions and 26 to pregnancy-related concerns.

Among social relations, husband-related issues were more common than in-laws or children issues. Concerns related to the personal and the parents category were identified through the in-depth interviews but they were less $<5 \%$ frequent. Among the social conditions, economy-related issues were the most common. Results for pregnancy-related concerns found that symptoms of pregnancy and changes due to pregnancy were the most common issues, whereas dependency and concern for unborn were comparatively less common.

\section{Phase 2-Quantitative results}

The mean age of 292 pregnant women for quantitative phase was 25.8 (SD 4.5) years and their mean education (in years) were 10.31 (SD 5.1). Other descriptors are found in Table 2.

Prevalence of depression, based on the cut-off score of 16 or more on CES-D scale, was $39.4 \%$

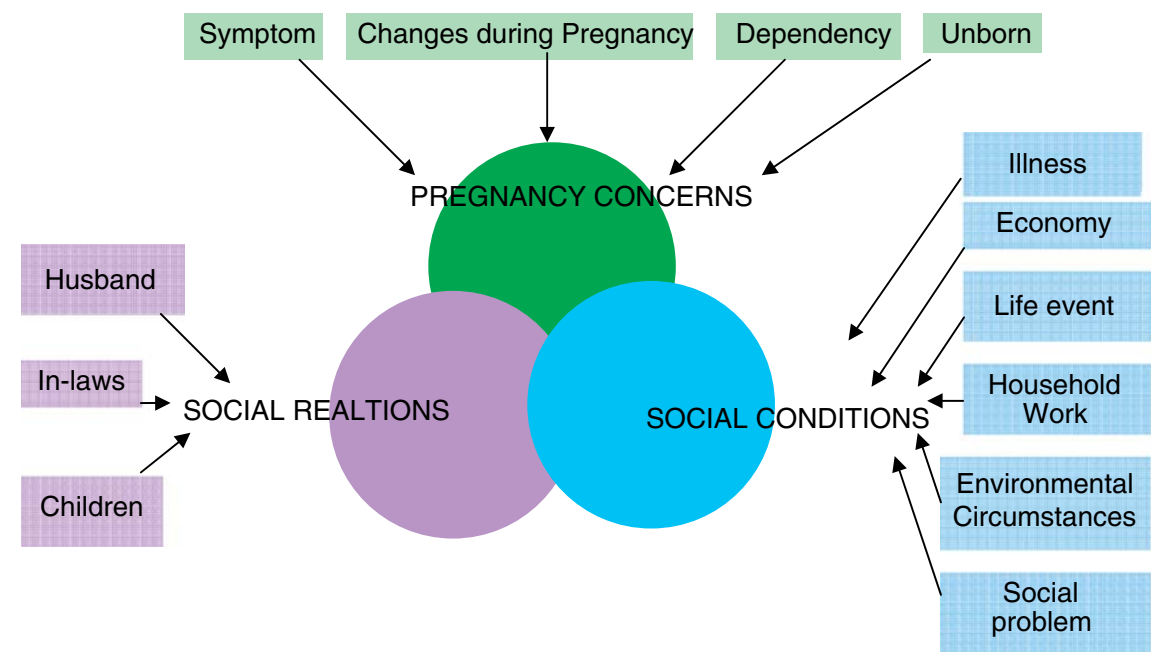

Fig. 1. Social environment framework for pregnant women. 
Table 3

Descriptive statistics of total, categories and subcategories of social environmental determinants among pregnant women in Karachi, Pakistan

\begin{tabular}{|c|c|c|c|c|c|}
\hline No. & Determinants $^{\mathrm{a}}$ & No. of determinants & Mean & SD & Range \\
\hline & Total determinants & 88 & 20.23 & 11.38 & $0-55$ \\
\hline & \multicolumn{5}{|l|}{ Themes } \\
\hline & Social relations & 18 & 2.93 & 2.57 & $0-12$ \\
\hline & Social conditions & 44 & 7.78 & 5.75 & $0-29$ \\
\hline & Pregnancy-related concerns & 26 & 9.39 & 4.71 & $0-21$ \\
\hline & \multicolumn{5}{|l|}{ Categories } \\
\hline 1 & Husband & 10 & 1.40 & 1.50 & $0-7$ \\
\hline 2 & In-laws & 6 & 0.66 & 0.91 & $0-4$ \\
\hline 3 & Children & 2 & 0.72 & 0.86 & $0-2$ \\
\hline 4 & Illness & 7 & 1.35 & 1.27 & $0-6$ \\
\hline 5 & Economy & 15 & 3.02 & 3.55 & $0-14$ \\
\hline 6 & Life events & 7 & 1.17 & 1.02 & $0-4$ \\
\hline 7 & Household work & 5 & 0.98 & 1.07 & $0-5$ \\
\hline 8 & Environmental circumstances & 6 & 0.75 & 0.92 & $0-4$ \\
\hline 9 & Social problems & 4 & 0.52 & 0.78 & $0-3$ \\
\hline 10 & Pregnancy symptoms & 8 & 3.07 & 1.71 & $0-7$ \\
\hline 11 & Concern for changes during pregnancy & 10 & 2.94 & 1.89 & $0-8$ \\
\hline 12 & Dependency due to pregnancy & 4 & 1.38 & 1.30 & $0-4$ \\
\hline 13 & Concerns of unborn baby & 4 & 2.0 & 1.06 & $0-4$ \\
\hline
\end{tabular}

${ }^{\mathrm{a}}$ Details of determinants under categories and subcategories are given in Appendix.

(112/292) among pregnant women. The mean CESD score (SD) was 14.53 (12.43).

Univariate linear regression (see Table 4) showed significant association between scores of themes of social relations, social conditions and pregnancyrelated concerns and total CES-D score. Results found that with one unit increase in the scores for social relation, social conditions and pregnancy concerns there was $0.64,0.50,0.55$ increase in the score on the CES-D scale. With each year of increase in education, there was a 0.17 decrease in scores on the CES-D scale, while age of mother, number of alive children and gestational age (in weeks) were not associated significantly with CES-D score. With increasing number of gravidity and abortion, there was an increase in CES-D scores.

Univariate linear regression showed significant association between categories and total CES-D scores (see Table 4). Increase in the scores on husband, in-laws and children categories led to 0.58 , 0.52 and 0.17 increase in the CES-D score, respectively. Among the social conditions categories, illness, economy, life events, household work, environmental circumstances and social problems led to an increase in the CES-D score.
Finally, among the pregnancy-related categories, pregnancy symptoms, pregnancy changes, dependency and unborn baby led to increases in the CESD scores.

Multivariate analysis results are presented in Table 5. In the first model, only major themes were entered. Among these, social relations and pregnancy-related concerns were significantly associated with total CES-D scores, whereas social conditions were not associated significantly. The adjusted $R^{2}$ for themes model was $46 \%$, meaning these variables explained approximately $46 \%$ of variance in depression among pregnant women.

All the categories along with age and education were entered in the second model. With increasing years in age, there was an increase in depression scores, while with increasing years in education, there was a decrease in the depression scores. Among the categories husband, in-laws, household work, pregnancy symptoms and pregnancy changes, there were increases in the CES-D scores, respectively. The adjusted $R^{2}$ for the categories model was $51 \%$. The categories related to children, illness, economy, life events, environmental circumstances, social problems, dependency and unborn child were not significant in the multivariate model. 
Table 4

Univariate linear regression analysis between categories and major themes of social environmental determinants and CES-D among pregnant women in Karachi

\begin{tabular}{|c|c|c|c|c|}
\hline & $B$ & Beta & $95 \% \mathrm{CI}$ & $P$ value \\
\hline \multicolumn{5}{|l|}{ Themes } \\
\hline Social relations & 3.05 & 0.64 & $2.63,3.47$ & $<.0001$ \\
\hline Social conditions & 1.08 & 0.50 & $0.86,1.29$ & $<.0001$ \\
\hline Pregnancy-related concerns & 1.45 & 0.55 & $1.20,1.71$ & $<.0001$ \\
\hline \multicolumn{5}{|l|}{ Categories } \\
\hline Age (years) & 0.18 & 0.06 & $-0.13,0.49$ & 0.26 \\
\hline Education of women (years) & -0.42 & -0.17 & $-0.70,-0.14$ & 0.003 \\
\hline Gestational age (weeks) & -0.07 & -0.05 & $-0.24,0.08$ & 0.36 \\
\hline Number of alive children & 0.91 & 0.08 & $-0.28,2.1$ & 0.13 \\
\hline Abortion & 3.45 & 0.20 & $1.49,5.41$ & 0.001 \\
\hline Gravida & 1.47 & 0.18 & $0.56,2.37$ & 0.002 \\
\hline Husband & 4.81 & 0.58 & $4.05,5.59$ & 0.00 \\
\hline In-laws & 7.2 & 0.52 & $5.85,8.54$ & 0.00 \\
\hline Children & 2.4 & 0.17 & $0.80,4.07$ & 0.004 \\
\hline Illness & 2.51 & 0.25 & $1.42,3.60$ & 0.00 \\
\hline Economy & 1.41 & 0.40 & $1.04,1.78$ & 0.00 \\
\hline Life event & 3.1 & 0.25 & $1.74,4.46$ & 0.00 \\
\hline Work related & 4.5 & 0.39 & $3.27,5.73$ & 0.00 \\
\hline Environmental circumstances & 3.06 & 0.22 & $1.55,4.58$ & 0.00 \\
\hline Social problems & 4.99 & 0.31 & $3.25,6.73$ & 0.00 \\
\hline Symptom & 3.30 & 0.45 & $2.56,4.05$ & 0.00 \\
\hline Concern for changes during Pregnancy & 3.23 & 0.49 & $2.57,3.89$ & 0.00 \\
\hline Dependency & 4.47 & 0.46 & $3.49,5.44$ & 0.00 \\
\hline Unborn baby & 3.26 & 0.27 & $1.96,4.56$ & 0.00 \\
\hline
\end{tabular}

\section{Discussion}

This is the first study to identify and study in detail the framework for social environmental determinants associated with depression among pregnant women in an urban area in Karachi, Pakistan. Consistent with the (Rahman et al., 2003) study in Pakistan, we also found a high prevalence of depression among pregnant women. Of the three social environmental themes, we found social relations and pregnancy concerns to be the most predictive of depression, whereas social conditions were not. This finding is also supported by other studies conducted elsewhere (Stevenson, Maton, \& Teti, 1999; Aro, Nyberg, Absetz, Henriksson, \& Lonnqvest, 2001; Lee \& Powers, 2002).

This study found that poor social relations with husband and in-laws were strongly related with depression among pregnant women, as has been found in other cultures as well (Barnet et al., 1996; Jain et al., 2004; Nitz et al., 1995; Stuchbery et al., 1998). Poor relationship with husband may be because of his extramarital affairs, physical and verbal abuse, not spending enough time with the family and putting unnecessary restriction on the women. Similarly, the study found that physical or verbal abuse and too much interference by the inlaws, either by living in a joint family system or by their influence over the household, affected the relationship. Another factor identified by the study is competition among different female members belonging to the same family, such as mother-in-law or sister-in-law. Competition is related to who has the more say in the family and whose decisions are being accepted. These again result in having a poor relationship with in-laws. Positive social relations have a protective effect against depression (McCormick et al., 1990; Mubarak, 1997; Norlander, Dahlin, \& Archer, 2000; Sprusinska, 1994; Wilkinson \& Marmot, 1998).

When studied separately, by various researchers, social conditions such as poverty, lack of education, unemployment, living in poor housing, life events and working conditions contribute individually and synergistically to depression among women (Bobak, Pikhart, Hertzman, Rose, \& Marmot (1998); Nilsson et al., 2003; Zimmermann-Tansella et al., 1991). This study also suggests that poor social conditions are related with increased depression among pregnant women but only in the univariate 
Table 5

Two multivariate linear regression models between categories and major themes of social environmental determinants and CES-D among pregnant women in Karachi

\begin{tabular}{|c|c|c|c|c|}
\hline & $B$ & Beta & $95 \% \mathrm{CI}$ & $P$ value \\
\hline \multicolumn{5}{|l|}{ Model for themes ${ }^{\mathrm{a}}$} \\
\hline Social relations & 2.25 & 0.47 & $1.68,2.82$ & $<.0001$ \\
\hline Pregnancy problems & 0.71 & 0.27 & $0.42,1.01$ & $<.0001$ \\
\hline \multicolumn{5}{|l|}{ Model for categories ${ }^{\mathrm{b}}$} \\
\hline Age & 0.38 & 0.14 & $0.15,0.61$ & 0.001 \\
\hline Education of women & -0.25 & -0.10 & $-0.45,-0.04$ & 0.02 \\
\hline Husband & 2.63 & 0.32 & $1.81,3.44$ & $<.0001$ \\
\hline In-laws & 2.37 & 0.17 & $0.95,3.79$ & 0.001 \\
\hline Children & 0.28 & 0.02 & $-1.16,1.72$ & ns \\
\hline Illness & -0.43 & 0.49 & $-1.41,0.54$ & ns \\
\hline Economy & 0.03 & 0.01 & $-0.35,0.42$ & ns \\
\hline Life events & 0.90 & 0.07 & $-0.17,1.98$ & ns \\
\hline Work related & 1.51 & 0.13 & $0.41,2.61$ & 0.007 \\
\hline Environmental circumstances & -0.65 & -0.04 & $-1.91,0.61$ & ns \\
\hline Social problems & 0.36 & 0.02 & $-1.14,1.86$ & ns \\
\hline Symptoms & 1.18 & 0.16 & $0.47,1.89$ & 0.001 \\
\hline Concern for changes during pregnancy & 0.67 & 0.10 & $-0.05,1.39$ & ns \\
\hline Dependency & 0.76 & 0.08 & $-0.34,1.87$ & ns \\
\hline Unborn & -0.72 & -0.06 & $-1.88,0.44$ & ns \\
\hline
\end{tabular}

${ }^{\text {a Adjusted }} R^{2}$ for themes $=46 \%$.

${ }^{\mathrm{b}}$ Adjusted $R^{2}$ for categories $=51 \%$.

analysis. However, in the multivariate model, only two of the social conditions namely household work and illness of the relatives were significantly associated with depression. Very few responsibilities and too many responsibilities have been found elsewhere to be associated with depression, while moderate responsibilities are favorable for women (Lee \& Powers, 2002). It has been argued that number of household responsibilities and illness of the relatives in Pakistani culture are more strongly associated with quality of social relations (Niaz, 2000). The better the social relations are with inlaws, husband and children, the more evenly the work is distributed in terms of responsibilities.

To date, no study in Pakistan has looked at pregnancy-related concerns in predicting depression. In the multivariate analysis, pregnancy symptoms and changes due to pregnancy were significantly associated with depression. A pregnant woman not only undergoes physical changes but along with this she has to make several adjustments to cope with the other daily responsibilities. Physical changes may cause her to become dependent on others for carrying out daily household chores, which also affects her socialization. The condition of pregnancy has been found to be associated with increased depression in many other studies con- ducted elsewhere (Dole et al., 2003; Mulder et al., 2002; Wadhwa et al., 2001).

This study supports the hypothesis that increasing age and lower levels of education are associated with increasing depression. Increasing biological age has been found to be associated with increased depression in other studies conducted in Pakistan (Husain et al., 2004; Nisar, Billoo, \& Gadit, 2004). Increasing level of education lead to increased social capital and that may increase the capability of women to cope with the social environment (Averina et al., 2005; Chaaya et al., 2002; Husain et al., 2004).

Depression refers to a clinical spectrum that ranges from a clinical syndrome (disorder) to the milder symptom of feeling down (Carson, Butcher, \& Mineka, 1998). The CES-D scale has been used cross-culturally and has shown good reliability for measuring depression among pregnant women and the general population (Gavin et al., 2005; Jain et al., 2004; Orr et al., 2002; Radloff, 1977; Sharp \& Lipsky, 2002; Tsutsumi et al., 2004). Depressive symptoms have been found to have the same economic burden on health care as the depressive disorders (Johnson, Weissman, \& Klerman, 1992). Therefore, it is important to note that use of continuous score of CES-D in the analysis not only 
determines the factors associated with depressive disorders but also those which are associated with depressive symptoms. These have a similar burden on the population and the same policy implications.

The study emphasizes the importance of social relations, which may be modifiable through interventions such as counseling and family support. Depression during pregnancy leads to adverse pregnancy outcomes such as low birth weight and preterm birth (Dole et al., 2003; Mulder et al., 2002; Wadhwa et al., 2001). Therefore, antenatal care programs may include counseling services for pregnant women in Pakistan. Intervention programs have successfully utilized traditional birth attendants and other health workers to develop support system for women in urban and rural areas (Jokhio, Winter, \& Cheng, 2005).

In this study, the sample of pregnant women was varied in terms of socio-economic status, trimester and parity. This provides an opportunity to determine factors of social environment in a comprehensive way and enables a framework to be generalized to a larger population. This is a cross-sectional study and it is therefore not able to establish a temporal relationship between the determinants and depression. We inquired about the difficult experiences perceived by woman during the last month in order to minimize recall bias. The refusal rate was not significant and analysis shows that a varied group with different parities, trimesters and social class was captured.

In conclusion, this study found high prevalence of depression among pregnant women of Karachi, Pakistan; the study highlights the importance of social relations compared to social conditions for determining depression in pregnant women.

\section{Acknowledgment}

The study was funded by Aga Khan University Research Council.

\section{Appendix}

Determinants of social relations

1. Husband

Second marriage by husband

Extramarital affair by husband

General worries of husband

Woman's restriction in making decision

No access to husband's money
Attention not given by husband

Restrictions of woman by husband

Verbal abuse by husband

Physical abuse by husband

Husband not having time for family

2. In-laws

Competition with in-laws

In-laws visiting at odd times

Physical abuse by in-laws

Interference by in-laws

Quarrel with relative

Major quarrel with in-laws

3. Children

Concern for children's education

Concern for children's future

Determinants of social conditions

4. Illness

Looking after sick relative

Parent's illness or injury

Sibling illness or injury

In-laws serious illness or injury

Children serious illness or injury

Husband's illness

Personal illness

5. Economy

Rented home

Owing money

Parent's financial problem

Non-earning member in the family

Less money for paying house rent

Having a small house

Husband's job security

Need money for food

Husband not doing any job

Need money for health facilities

Need money for buying house

Inflated prices of common goods

Need money for clothing

Need money for children's education

Future financial needs

6. Life events

Death of parents

Death of child

Abortion

Death of close relative

Getting married to someone outside family

Suicidal attempt

Birth of handicapped child 
7. Household work

Too many responsibilities

Preparing meals

Problem with maid

Looking after the children

Job problem

\section{Environmental circumstances}

Parent's living far

Troublesome neighbors

Living alone

Safety and security

Husband being abroad

Problem due to shifting

9. Social problems

Husband addicted to drugs

Too many people in the house

Living with in-laws

Sibling marriage

Determinants of pregnancy-related concerns

10. Pregnancy symptoms

Weight gain

Headache

Feeling unwell

Eating preferences

Difficulty in sleep

Bleeding per vagina

Vomiting during pregnancy

Not feeling baby's movement

11. Changes during pregnancy

Physical appearance

Discontinuation of job

Shopping for the unborn baby

Access to health care

Late for work

Unwanted pregnancy

Difficulty in getting up in the morning

Difficulty in prayers

First pregnancy

Previous delivery by caesarian-section

Previous delivery outcome

12. Dependency due to pregnancy

Restricted socialization

Dependency for doing household work

Difficulty in traveling

General dependence

13. Concern of unborn baby

Fear of baby girl

Concerns about well-being of the baby
Concerns about bringing up of the baby

Appearance of the baby

\section{References}

Ali, B. S., Rahbar, M. H., Naeem, S., Tareen, A. L., Gul, A., \& Samad, L. (2002). Prevalence of and factors associated with anxiety and depression among women in a lower middle class semi-urban community of Karachi, Pakistan. Journal of Pakistan Medical Association, 52(11), 513-517.

Aro, A. R., Nyberg, N., Absetz, P., Henriksson, M., \& Lonnqvest, J. (2001). Depressive symptoms in middle aged women are more strongly associated with physical health and social support than with socioeconomic factors. Nordic Journal of Psychiatry, 55, 191-198.

Averina, M., Nilssen, O., Brenn, T., Brox, J., Arkhipovsky, V. L., \& Kalinin, A. G. (2005). Social and lifestyle determinants of depression, anxiety, sleeping disorders and self-evaluated quality of life in Russia A population-based study in Arkhangelsk. Social Psychiatry and Psychiatric Epidemiology, 40(7), 511-518 (Epub 2005 August 15).

Barnet, B., Joffe, A., Duggan, A. K., Wilson, M. D., \& Repke, J. T. (1996). Depressive symptoms, stress, and social support in pregnant and postpartum adolescents. Archives of Pediatrics and Adolescent Medicine, 150(1), 64-69.

Bennett, H. A., Einarson, A., Taddio, A., Koren, G., \& Einarson, T. R. (2004). Prevalence of depression during pregnancy: Systematic review. Obstetrics \& Gynecology, 103(4), 698-709.

Bobak, M., Pikhart, H., Hertzman, C., Rose, R., \& Marmot, M. (1998). Socioeconomic factors, perceived control and selfreported health in Russia. A cross sectional survey. Social Science \& Medicine, 47(2), 269-279.

Carson, R. C., Butcher, J. N., \& Mineka, S. (1998). Abnormal psychology and modern life. In Stress and adjustment disorders (10th ed., pp. 118-155). New York: Longman.

Chaaya, M., Campbell, O. M., El Kak, F., Shaar, D., Harb, H., \& Kaddour, A. (2002). Postpartum depression: Prevalence and determinants in Lebanon. Archive of Women's Mental Health, 5(2), 65-72.

Dole, N., Savitz, D. A., Hertz-Picciotto, I., Siega-Riz, A. M., McMahon, M. J., \& Buekens, P. (2003). Maternal stress and preterm birth. American Journal of Epidemiology, 157(1), $14-24$.

Gavin, N. I., Gaynes, B. N., Lohr, K. N., Meltzer-Brody, S., Gartlehner, G., \& Swinson, T. (2005). Perinatal depression: A systematic review of prevalence and incidence. Obstetrics \& Gynecology, 106(5), 1071-1083.

Government of Pakistan (1998). Population and housing census, Islamabad.

Huizink, A. C., Robles de Medina, P. G., Mulder, E. J. H., Visser, G. H. A., \& Buitelaar, J. K. (2003). Multidimensional models of prenatal distress in normal risk pregnancy. Available at: http://www.igitur-archieve.library.uu.nl/digiarchief/ dip/dissertations/1933819/c7.pdf

Husain, N., Creed, F., \& Tomenson, B. (2000). Depression and social stress in Pakistan. Psychological Medicine, 30, 395-402.

Husain, N., Gater, R., Tomenson, B., \& Creed, F. (2004). Social factors associated with chronic depression among a 
population based sample of women in rural Pakistan. Social Psychiatry and Psychiatric Epidemiology, 39, 618-624.

Jain, D., Sanon, S., Sadowski, L., \& Hunter, W. (2004). Violence against women in India: Evidence from rural Maharashtra, India. Rural Remote Health, 4(4), 304-308 (Epub November 22).

Johnson, J., Weissman, M. M., \& Klerman, G. L. (1992). Service utilization and social morbidity associated with depressive symptoms in the community. Journal of American Medical Association, 267, 1478-1483.

Jokhio, A. H., Winter, H. R., \& Cheng, K. K. (2005). An intervention involving traditional birth attendants and perinatal and maternal mortality in Pakistan. New England Journal of Medicine, 352, 2091-2099.

Koniak-Griffin, D., Lominska, S., \& Brecht, M. L. (1993). Social support during adolescent pregnancy: A comparison of three ethnic groups. Journal of Adolescence, 16(1), 43-56.

Lee, C., \& Powers, J. R. (2002). Number of social roles, health and well being in three generations of Australian Women. International Journal of Behavioural Medicine, 9(3), 195-215.

McCormick, M. C., Brooks-Gunn, J., Shorter, T., Holmes, J. H., Wallace, C. Y., \& Heagarty, M. C. (1990). Factors associated with smoking in low-income pregnant women: Relationship to birth weight, stressful life events, social support, health behaviors and mental distress. Journal of Clinical Epidemiology, 43(5), 441-448.

Mubarak, A. R. (1997). Acomparative study on family, social supports and mental health of rural and urban Malay women. Medical Journal of Malaysia, 52(3), 274-284.

Mulder, E. J., Robles de Medina, P. G., Huizink, A. C., Van den Bergh, B. R., Buitelaar, J. K., \& Visser, G. H. (2002). Prenatal maternal stress: Effects on pregnancy and the (unborn) child. Early Human Development, 70(1-2), 3-14.

Mumford, D. B., Minhas, F. A., Akhtar, I., Akhter, S., \& Mubbashar, M. H. (2000). Stress and psychiatric disorder in urban Rawalpindi. Community survey. British Journal of Psychiatry, 177, 557-562.

Mumford, D. B., Nazir, M., Jilani, F. U., \& Baig, I. Y. (1996). Stress and psychiatric disorder in the Hindu Kush: A community survey of mountain villages in Chitral, Pakistan. British Journal of Psychiatry, 168(3), 299-307.

Mumford, D. B., Saeed, K., Ahmad, I., Latif, S., \& Mubbashar, M. H. (1997). Stress and psychiatric disorder in rural Punjab. A community survey. British Journal of Psychiatry, 170, 473-478.

Niaz, U. (2000). Women's mental health, Karachi, Pakistan. Pakistan Psychiatric Society. (Monograph series II).

Niaz, U. (2001). Overview of women's mental health in Pakistan. Pakistan Journal of Medical Sciences, 17(4), 203-209.

Nilsson, P. M., Engberg, M., Nilsson, J. A., Karlsmose, B., \& Lauritzen, T. (2003). Adverse social factors predict early ageing in middle-aged men and women: The Ebeltoft Health Study, Denmark. Scandinavian Journal of Public Health, 31(4), 255-260.

Nisar, N., Billoo, N., \& Gadit, A. A. (2004). Prevalence of depression and the associated risks factors among adult women in a fishing community. Journal of Pakistan Medical Association, 54(10), 519-525.

Nitz, K., Ketterlinus, Rd., \& Drandt, L. J. (1995). The role of stress, social support, and family environment in adolescent mothers' parenting. Journal of Adolescent Research, 10(3), 358-382.

Norlander, T., Dahlin, A., \& Archer, T. (2000). Health of women: Associations among life events, social support, and personality for selected patient groups. Psychological Reports, 86(1), 76-78.

Orr, S. T., James, S. A., \& Blackmore Prince, C. (2002). Maternal prenatal depressive symptoms and spontaneous preterm births among African-American women in Baltimore, Maryland. American Journal of Epidemiology, 156(9), 797-802.

Rabbani, F., \& Raja, F. F. (2000). The minds of mothers: Maternal mental health in an urban squatter settlement of Karachi. Journal of Pakistan Medical Association, 50(9), 306-312.

Radloff, L. S. (1977). The CES-D scale: A self report depression scale for research in the general population. Applied Psychological Measurement, 1, 385-401.

Rahman, A., Iqbal, Z., \& Harrington, R. (2003). Life events, social support and depression in childbirth: Perspectives from a rural community in the developing world. Psychological Medicine, 33(7), 1161-1167.

Riso, L. P., Miyatake, R. K., \& Thase, M. E. (2002). The search for determinants of chronic depression: A review of six factors. Journal of Affected Disorder, 70(2), 103-115.

Sharp, L. K., \& Lipsky, M. S. (2002). Screening for depression across the lifespan: A review of measures for use in primary care settings. American Family Physician, 66(6), 1001-1008.

Sprusinska, E. (1994). The Family APGAR Index: Study on relationship between family function, social support, global stress and mental health perception in women. International Journal of Occupational Medical \& Environmental Health, 7(1), 23-32.

Stevenson, W., Maton, K. I., \& Teti, D. M. (1999). Social support, relationship quality, and well being among pregnant adolescents. Journal of Adolescence, 22(1), 109-121.

Stotland, N. L. (1995). Psychiatric issues. In W. M. Barron, \& M. D. Kindheimer (Eds.), Medical disorders during pregnancy (pp. 519-531). St Louis: Mosbys.

Stuchbery, M., Matthey, S., \& Barnett, B. (1998). Postnatal depression and social support in Vietnamese, Arabic and Anglo-Celtic mothers. Social Pyschiatry and Psychiatric Epidemiology, 33(10), 483-490.

Tsutsumi, A., Izutsu, T., Akramul Islam, M. D., Amed, J. U., Nakahara, S., Takagi, F., et al. (2004). Depressive status of leprosy patients in Bangladesh: Association with self-perception of stigma. Leprosy Review, 75(1), 57-66 (Erratum in: Leprosy Review, 75(2), 205).

Wadhwa, P. D., Culhane, J. F., Rauh, V., Barve, S. S., Hogan, V., Sandman, C. A., et al. (2001). Stress, infection and preterm birth: A biobehavioural perspective. Paediatric and Perinatal Epidemiology, 15(Suppl. 2), 17-29.

Wilkinson, R., \& Marmot, M. (Eds.). (1998). Social determinants of health: The solid facts. Available at: http://www.who.dk/ document/59555.pdf

Zimmermann-Tansella, C., Donimi, S., Lattanzi, M., Siciliani, O., Turrina, C., \& Wilkinson, G. (1991). Life events, social problems and physical health status as predictors of emotional distress in men and women in a community setting. Psychological Medicine, 21(2), 505-513. 